\title{
Effective communication in science and technology for the space workforce development in Latin- America
}

The relics found in several regions of South, Central and North America demonstrate the ancient interest in the heavens that led to exploring the unknown, discover new worlds and push the boundaries of our scientific and technical limits. The intangible desire to explore and challenge the boundaries of what we know and provide benefits to our society. Through addressing the challenges related to human space development ${ }^{1}$ we expand technology, create new industries, and help to foster a peaceful connection with other nations. ${ }^{2}$ In the attempt to promote space development, the Andean Road Countries for Science and Technology ARCST is the attempt to create a state of-theart, next-generation Latin-American workforce in Space Technology Applications. ${ }^{3}$ The handful of successes to date and the long menu of areas of potential interest for the future are encouraging, as is the resourcefulness of ARCST members in establishing and maintaining linkages with the international scientific community despite enormous challenges in the Latin-American region. ${ }^{4}$ Yet it is still difficult to develop a competitive Latin-America science and technology (S\&T) base and commercially viable innovative businesses in S\&T. ${ }^{5}$

Science is practically international; this is true for research in areas such as the health sciences, ecology, and climate studies. Scientific research is concentrated in the developed market and plane economies. ${ }^{6}$ During the last century, most scientific communication happened between developed countries. ${ }^{7}$ This fact seems to have marginalized developing countries from the mainstream scientific communication process. Scientific communication occurs through formal and informal channels and it seems to be the most important challenge to overcome in the Latin American region. This problem was constantly mentioned during the last workshop of the ARCST and different ideas emerged on how to solve them. Resource sharing, networking, creation of more communication channels were suggested as initial solutions to this problem, as they depend strictly on the main factors involved in the space area.

Effective communication in science involves not only technical knowledge, but it also goes beyond. It draws on a wide range of disciplines including science, communication, education, psychology, philosophy, and sociology. ${ }^{8}$ Although few academic resources exist to guide the teaching of communication in multicultural environments, ${ }^{9}$ it is the engagement or interaction between actors of the scientific Latin-American community that is pivotal in facilitating the engagement with science in the region and overseas. Limited research funds are currently spread over too many institutes and too many programs and those activities that are not making significant contributions to science or economic development sometimes are abandoned, according to representatives of different Latin-American countries during our workshop held on October 2018. Several steps must be taken to provide more opportunities for young scientists and engineers to assume responsible positions within the universities and research institutes that command international respect. ${ }^{10}$ With reasonable funding and more focused and determined efforts in the important areas of Space Technology, ARCST should be able to move towards a viable knowledge-based economy.
Volume 3 Issue 3 - 2019

\author{
Xiao Xin Zhang,' Marco A Cabero² \\ 'Department of Communication, Communication University of \\ China, P. R. China \\ ${ }^{2}$ Chairman \& Founder, Andean Road Countries for Science and \\ Technology, China
}

Correspondence: Xiao Xin Zhang, Department of Communication, Communication University of China, Beijing, P. R. China, 100024, Email zhangxiaoxin@cuc.edu.cn

Received: August 14, 2019 | Published: September 10, 2019

Despite the economic limitations, curiosity and exploration have remained vital to the human spirit for going deeper into space. This is the reason why we invite the Latin-American countries today and the generations of tomorrow to join the Andean Road Countries for Science and Technology (ARCST) on this exciting journey. The first step in embarking on a long and challenging journey involves laying solid groundwork for a successful endeavor. For that, the ARCST serves as the first Latin-American organization focused on tackling the challenges, opportunities and innovative approaches to develop the current and future scientific and technological space workforce.

After the workshop organized in October 2018 where several LatinAmerican and Chinese young professionals, senior scientists, and professors gathered for the first time at Beihang University to discuss the technical problems in the space-related field, the challenges faced by different countries, which are mostly economic, and the plausible strategies to minimize them..$^{11,12}$ The lack of scientific communication for the developmen of projects and solutions for the region, was the main indicator for the absence of common technological progress. As a general agreement, cooperation, permanent communication, ${ }^{13-15}$ replicas of solutions to similar problems were accepted as strategies to develop the technological space workforce in the region. Fostering the Latin-American talent seems to be a fundamental task to develop the space workforce. Developing common strategies, the synergy of actors involved, the promotion and cooperation among countries, the support professionals and experts could certainly benefit the development of its space workforce, expand its technology, create new industries, and help to foster peaceful cooperation with other nations.

\section{Acknowledgments}

The authors acknowledge the collaboration and support of Prof. Wang Xinsheng and Ambassador Raimundo González Aninat as well as the Latinamerican professionals who participated in our first workshop proposing their ideas.

\section{Conflicts of interest}

Authors declare that there is no conflict of interest. 


\section{References}

1. Space Technology Grand Challenges. NASA; 2010.

2. Avci F, Wang X, Cabero Zabalaga MA, et al. EcoBeltSat-1: The Belt and Road Satellite Project. Proceedings of the International Astronautical Congress; 2019.

3. https://onlinemac.wixsite.com/arcs

4. Marchini J, Morales J, Roffinelli G. Conflicts between Latin American Countries and Transnational Corporations: The challenges of the region in the face of asymmetrical investment treaties. IISD; 2018.

5. Innovating for growth in Latin America. World Bank; 2017.

6. Samarajiva R. Implications of technological change for scientific communication in the third world a case study. Asian Journal of Communication. 1990;1(1):81-97.

7. Garfield E. Mapping science in the Third World. Science and Public Policy. 1983;10(3):112-127.

8. Mulder HAJ, Longnecker N, Davis LS. The state of science communication programs at Universities around the world. Science Communication. 2008;30(2):277-287.
9. Mercer-Mapstone L, Kuchel L. Core Skills for Effective Science Communication: A Teaching Resource for Undergraduate Science Education. International Journal of Science Education, Part B. 2017;7(2):1-5.

10. Rodriguez A. Young Scientists, Investing in Tomorrow. World Bank blogs; 2016.

11. Cabero Z Marco A. Road of the Andes for science and technology. Revista Persea; 2019.

12. http://spanish.chinatoday.com.cn/2018/wgrzzg/201901/ t20190110 800153893. html

13. Uzun L. Utilising Technology for Intercultural Communication in Virtual Environments and the Role of English. Procedia - Social and Behavioral Sciences. 2014;116:2407-2411.

14. Lu WH, Yang CC, Peng H, et al. The Impact of Computer-Mediated Intercultural Communication on Learner's Cultural Awareness and Sensitivity: A Case Study. Chicago, IL: Association for Educational Communications and Technology; 2004. 7 p.

15. Lustig MW, Koester J. Intercultural Competence: Interpersonal Communication across Cultures. Boston: Pearson Education Inc., Allyn \& Bacon Publishing; 2010. 